Acta Universitatis Wratislaviensis • No 4055

Literatura i Kultura Popularna XXVII, Wrocław 2021

https://doi.org/10.19195/0867-7441.27.30

\title{
Michał Pick
}

ORCID: 0000-0001-9599-0825

Uniwersytet Wrocławski

\section{Poetyka wideoklipu muzycznego}

Słowa kluczowe: wideoklip muzyczny, teledysk, wideo, klip, poetyka

Keywords: music video, video, clip, poetics

Wideoklip jako odrębny gatunek sztuk audiowizualnych jest stosunkowo młodym zjawiskiem, choć wskazanie momentu, jaki można by arbitralnie uznać za jego narodziny, jest zadaniem niezwykle trudnym. To forma muzyczno-filmowa, która od początku swojego istnienia stale ewoluowała i ewoluuje nadal wraz z postępem technologicznym oraz wynikającymi z niego dobrodziejstwami. Jest przy tym bezpośrednio związana z rozwojem kinematografii, telewizji i — nieco późniejszych - programów muzycznych, w których emitowano, pełniące początkowo głównie funkcję promocyjną, klipy.

Niełatwe do ustalenia zdaje się nawet znaczenie terminu „wideoklip”. Specjalistyczna literatura posługuje się w znacznej mierze podobnymi definicjami, które zebrane w Słowniku wyrazów obcych tworzą następujące hasło: „kilkuminutowy program TV zrealizowany na temat piosenki, stanowiącej jego warstwę dźwiękową"1. Analogiczną definicję proponuje popularna internetowa encyklopedia, utożsamiająca wideoklip z ,formą sztuki filmowej w połączeniu z utworem muzycznym, inspirowaną filmem reklamowym. $Z$ reguły jego fabuła nawiązuje do tematu utworu. Rozpowszechniony od początku lat 80., m.in. za sprawą amerykańskiej telewizji muzycznej MTV"2. Na gruncie polskim pierwszą próbę zdefiniowania interesującego nas tu pojęcia podjęła teoretyk filmowa Grażyna Stachówna, która wideoklip potraktowała jak określenie synonimiczne teledysku, pisząc: „Wideoklip lub teledysk - krótki program telewizyjny zarejestrowany metodą

1 W. Kopaliński, Wideoklip, [hasło w:] idem, Słownik wyrazów obcych i zwrotów obcojęzycznych, Warszawa 2000, s. 537.

2 Wideoklip, Wikipedia, https://bit.ly/3eCsgpo (dostęp: 8.09.2020). 
wideo na taśmie magnetycznej, będący wizualnym, zamkniętym dramaturgicznie zobrazowaniem jakiegoś utworu muzycznego, najczęściej piosenki”3. Własną propozycję podał także Marek Nalikowski: ,[wideoklip] to krótki film muzyczny, będący ilustracją piosenki i reklamą płyty, z której ona pochodzi [...]. Klip to obraz, który jest echem muzyki’"4. Bardziej kompleksową próbę zdefiniowania kłopotliwego terminu podjął Piotr Zawojski w książce Elektroniczne obrazoświaty, tak pisząc o tym gatunku: „Wideoklip to oryginalny produkt telewizyjnego medium, zarazem stanowiący formę kolażową złożoną z elementów najrozmaitszej proweniencji. Mieszanina elementów wywodzących się z tradycji filmu, muzyki, plastyki, pantomimy, teatru, estrady [...]"5.

Już na wstępie musimy zauważyć silne związki czy nawet programowe „uzależnienie" wideoklipu od innych gałęzi sztuki, należy tym samym wskazać na jego polisemiotyczny charakter i wysoką intertekstualność. Z pomocą w próbie terminologicznego uściślenia przychodzi nam również Słownik terminów filmowych, w którym znajdziemy następującą definicję:

Wideoklip to krótki utwór telewizyjny zrealizowany przy użyciu nowoczesnych technik elektronicznej rejestracji i montażu, często z wykorzystaniem efektów wizualnych i dźwiękowych, produkowany z myślą o promocji piosenki, nagrania płytowego, wykonawcy czy filmu ${ }^{6}$.

W literaturze obcojęzycznej zaś szczególną popularnością cieszy się opracowanie Marshy Kinder. Oprócz autorskiej propozycji typologii wideoklipów badaczka zaproponowała także własną charakterystykę tego gatunku, tłumacząc go jako „formę rozszerzenia unikalnych możliwości estetycznych awangardy wcześniej ograniczonych do tworzenia filmów niezależnych i video-artu. To nowa kombinacja muzyki i obrazów, redefiniująca relacje audiowizualne w mediach masowych [...]"7. Sedna sprawy dotyka w moim przekonaniu Urszula Jarecka, która sięga do etymologii nazwy „wideoklip”, wskazując przy okazji na jej dwuczłonowość:

Wideoklip to zrost dwóch słów: pochodzącego z łaciny video (widzę) i angielskiego wieloznacznego rzeczownika clip. Clip może być przyborem do łączenia rzeczy albo fragmentem większej całości - wycinkiem np. z filmu, czynnością łączenia lub cięcia - dopasowywania, jakiejś modyfikacji funkcjonalnej, przysposobienia, przystosowania, a także krótkim, szybkim ciosem i gwałtownym ruchem ${ }^{8}$.

To etymologiczne wyjaśnienie daje nam podstawę do rozumienia wideoklipu jako połączenia „wideo” (nagrania sekwencji obrazów dokonanego techniką elektroniczną, pozwalającą na jego natychmiastowe przetwarzanie i transmitowa-

3 G. Stachówna, O wideoklipach, „Powiększenie” 1987, nr 3-4, s. 166.

${ }^{4}$ M. Nalikowski, Estetyka wideoklipu, „Akcent” 1991, nr 1, s. 178.

5 P. Zawojski, Elektroniczne obrazoświaty. Między sztuka a technologia, Kielce 2000, s. 51.

${ }^{6}$ M. Hendrykowski, Stownik terminów filmowych, Poznań 1994, s. 322.

${ }^{7}$ M. Kinder, Teledyski a widz: telewizja, ideologia i marzenia senne, „Przekazy i Opinie” 1988, nr 1-2, s. 95.

8 U. Jarecka, Świat wideoklipu, Warszawa 1999, s. 110. 
nie) i „klipu” (krótkiego filmu bądź jego fragmentów, łączonych w większą całość na zasadzie wizualnej mozaiki). Jak więc widzimy, „w i de o klip” jest pojęciem bardzo szerokim. W takim ujęciu jest nim zarówno reklama, spot wyborczy, jak i krótkie formy sztuki filmowej stworzone „techniką klipową"9, charakteryzujące się fragmentarycznością, często nielinearną budową, która służy realizacji estetyki powtórzeń i z(a)nikania ${ }^{10}$. Dlatego też w polskiej literaturze częściej spotykanym terminem na określenie tego, co zachodni badacze zwykli nazywać music video, jest „teledysk”, konotujący połączenie ruchomego obrazu z utworem muzycznym. W definicjach podkreśla się często związek teledysku z filmem reklamowym, wskazując tym samym na prymarną funkcję promocyjną teledysków ${ }^{11}$.

Zważywszy na zaznaczane niemal we wszystkich definicjach gatunkowe zróżnicowanie, przystępując do analizy wideoklipu, musimy zdawać sobie sprawę z tego, że jest on właściwie artystycznym kolażem stworzonym $\mathrm{z}$ wielu form. Jarecka wideoklip nazywa nawet „koktajlem konwencji, gatunków i stylów”, podkreślając jego

współbrzmienie, harmonijną syntezę, integrację niejednorodnych składników przekazu: muzyki, słowa, obrazu filmowego oraz tego, co niesie ze sobą osadzenie w kontekście - w MTV i innych telewizjach muzycznych ${ }^{12}$, stanowiących znakomite przykłady neo-telewizji, świadectwa rozwoju epoki multimediów ${ }^{13}$.

Pojawiający się w tym miejscu termin „multimedium”, na gruncie działań artystycznych rozumiany jako ,widowisko operujące równocześnie środkami różnych dziedzin sztuki i rozmaitymi formami przekazu: łączące muzykę, poezję, teatr, sztuki plastyczne oraz wyzyskujące środki techniczne filmu i telewizji”'14, pozwala nam zastosować względem wideoklipu propozycje kategorii genologii multimedialnej Edwarda Balcerzana. Forma ta jawi się w tym ujęciu jako gatunek polimedialny ${ }^{15}$, balansujący na granicy dwóch proponowanych przez bada-

9 Także zwiastun filmowy, zwany również trailerem, jako osobny rodzaj przekazu.

10 Zob. np. P. Virilio, Prędkość i polityka, przeł. S. Królak, Warszawa 2008 lub J. Baudrillard, Gra resztkami, przeł. A. Szahaj, [w:] Postmodernizm a filozofia, red. S. Czerniak, A. Szahaj, Warszawa 1996.

11 Obydwa terminy, to jest ,teledysk” i „wideoklip”, bywają używane zamiennie, jak chociażby w definicji Grażyny Stachówny. Polemiczny charakter ma natomiast artykuł Urszuli Jareckiej, co zostało zasygnalizowane już w jego tytule: Od teledysku do wideoklipu; tekst znalazł się w pracy zbiorowej Nowe media w komunikacji społecznej w XX wieku, pod redakcją Maryli Hopfinger (Warszawa 2002). W niniejszym artykule ,teledysk" traktuję jako pojęcie synonimiczne nie wideoklipu jako takiego, a interesującego mnie wideoklipu muzycznego, co w oparciu na przywołanych wcześniej definicjach zdaje się rozsądnym konsensusem.

12 Cytowany fragment pochodzi z książki wydanej w roku 1999, wówczas (jeszcze) telewizje muzyczne, takie jak MTV, były podstawowym kontekstem dla wideoklipów, dzisiaj w to miejsce wstawilibyśmy raczej Internet.

13 U. Jarecka, Świat wideoklipu..., s. 101-102.

14 M. Głowiński et al., Słownik terminów literackich, red. J. Stawiński, Wrocław 1998, s. 328.

15 Inaczej hybrydyczny. W wideoklipie między obrazem, dźwiękiem a słowem zachodzi stała współpraca, wszystkie te sfery nie tylko się przenikają, ale wręcz uzupełniają wzajemnie. W przy- 
cza quasi-rodzajów: eseistycznego, charakteryzującego się refleksyjnością, która skłania do przyjęcia proponowanego punktu widzenia, mając w sobie coś z retoryki wychowawczej, i felietonowego, którego intencją jest eksploracja magazynu stereotypów i zabawa (często ironiczna) formą oraz gra znaków (w tym przypadku wizualnych) ${ }^{16}$.

Biorąc pod uwagę wymienione aspekty, powinniśmy zauważyć, że prawidłowy proces dekodowania teledysku, odczytanie go jako oryginalnego tekstu kultury popularnej, uzależnione jest od znajomości i wyodrębnienia technik, które warunkują jego swoistą poetykę. Są to techniki i metody powszechnie stosowane w kinematografii i innych sztukach wizualnych oraz audiowizualnych, których związek z wideoklipem wydaje się najbardziej oczywisty. W tym ujęciu poetykę wideoklipu muzycznego należałoby więc traktować jako zbiór swoistych cech o charakterze formalnym i estetycznym, warunkujących gatunkową odrębność i reguły organizacji elementów składowych interesującego nas tu medium.

Rozwijając zagadnienie poetyki wideoklipu i pisząc o jednostkach klipowej „gramatyki”, Jarecka wyróżnia takie komponenty, jak: rytmiczny montaż, kontrast planów, mnogie spowolnienia, zabawy ostrością, światłem i kątem, a także samą konwencją i gatunkami, wprowadzające elementy fabularyzowane, które powodują, że mamy do czynienia z artystycznym obrazem uzupełniającym nagranie muzyczne w sposób oryginalny i metaforyczny. Autorka przywoływanej tu monografii wskazuje także na pragmatyczne wykorzystanie osiagnnięć fotografii (echa obrazowego, solaryzacji, fotomontażu, natężenia i nasycenia barw), którym Marek Hendrykowski w Semiotyce ruchomych obrazów przypisuje znaczenie psychologiczne, pisząc:

Złożona funkcja barwy w filmie nie daje się sprowadzić jedynie do mniej lub bardziej kompletnej reprodukcji barw świata zewnętrznego. Ukazujące się na ekranie zestawienia kolorystyczne, ich układy, zestroje, tonacje, dominanty itp., wywołują każdorazowo określony efekt optyczny i psychologiczny ${ }^{17}$.

Wymienione elementy nie tylko sugestywnie zwracają uwagę odbiorcy na ważniejsze fragmenty, ale nadają wideoklipowi płynności, współgrają z jego często nielinearną budową czasowo-przestrzenną. To w końcu rytm jest czynnikiem decydującym o wrażeniu integralności dzieła, wchodzi w sferę semiotyki przekazu kinematograficznego na równi z jego stroną wizualną. Jak podkreśla Hendrykowski: „Dźwięk tworzy integralny element kompozycji ruchu w filmie. Ruch potrzebuje rytmu"18.

padku gatunków polimedialnych istotny jest przede wszystkim stopień podobieństwa międzygatunkowego. Jak pisze Balcerzan: „tutaj jeden gatunek (np. film fabularny) może być mniej lub bardziej wiarygodną metaforą innego gatunku (np. powieści)" - idem, W strone genologii multimedialnej, „Teksty Drugie. Teoria literatury/krytyka/interpretacja” 1999, nr 6 (59), s. 17.

16 Ibidem, s. 23-24.

17 M. Hendrykowski, Semiotyka ruchomych obrazów, Poznań 2014, s. 81.

18 Ibidem, s. 77. 
Na różne parametry ruchu, składające się na wewnętrzną złożoność obrazu, takie jak ruch strumienia elektronów, ilościowy „ruch” jakości poszczególnych punktów obrazu (jasność, nasycenie barw), ruch odniesień między punktami obrazu lub częściami obrazu (przez miksowanie, formatowanie i modulację), ruch między warstwami przedmiotowymi (obraz z kamery) a nieprzedmiotowymi (kolor, rastrowanie, solaryzacja), wskazuje także Wolfgang Preikschat ${ }^{19}$. Aktywność owych „martwych” elementów sprzyja manipulacji, której poddawani jesteśmy jako odbiorcy - ulegamy wrażeniu iluzorycznego realizmu, którego charakter nie jest wcale mimetyczny, a raczej konceptualny.

Uwagi te możemy odnieść także do otaczającej nas rzeczywistości. Rytmu potrzebują również statyczne dzieła architektoniczne. Ich kształty, ogólna kompozycja, rozmieszczenie okien i kolejnych kondygnacji porządkują „obraz” budynku, nadając mu cech spójności. Zależność ruchu i rytmu jest czymś, co funkcjonuje głęboko w ludzkiej podświadomości, dopiero zaburzenie tej równowagi wywołuje u odbiorcy poczucie dysonansu. Rytm, co potwierdza przykład z dziełami architektury, jest podstawowym czynnikiem integralności rzeczywistości odbieranej za pomocą zmysłów. W tym kontekście należy wspomnieć o koncepcji „montażu atrakcji" Siergieja Eisensteina, która także znajduje zastosowanie w przypadku wideoklipów. Montaż ma według założeń tego reżysera oddziaływać bezpośrednio na percepcję odbiorcy. Stosowanie serii montażowych tez i antytez dążących do syntezy oraz powtarzanie wybranych kadrów przypomina podział piosenki na zwrotki i refreny. Kolejne kadry bywają montowane na zasadzie luźnych skojarzeń (bądź ich pozornego braku). W ten sposób tworzy się ,atrakcjony”, które Eisenstein uważa za podstawową jednostkę budulcową filmu ${ }^{20}$. Swobodne łączenie kolejnych atrakcjonów ma nie tylko pobudzać uwagę biernego widza, lecz także nadawać rytm i kierunek ,czy tania” dzieła, co możliwe jest dzięki stosowaniu tak zwanych fraz-wskazówek powstałych w wyniku redukcji związków wewnątrzi zewnątrzfilmowych ${ }^{21}$. Pokrewieństwo montażu atrakcji oraz estetyki powtórzeń jest w tym miejscu nader widoczne, podobnie jak ich zastosowanie w teledyskach, których konstrukcja opiera się na łączeniu serii krótkich klipów skondensowanych do postaci narracyjnej formy, zbudowanej wokół „atrakcjonów” - wyjątkowo istotnych w przypadku krótkiego materiału audio-wideo. „Atrakcyjność” wideoklipu w dużej mierze zależy od umiejętności montażu takich elementów, jak tempo, kierunek ruchu czy czas trwania poszczególnych planów, oraz manipulacji owymi montażowymi tezami i antytezami.

Urszula Jarecka w cytowanej już pracy poświęca osobny rozdział charakterystycznym cechom wideoklipu. Przytoczone wcześniej elementy klipowej gra-

19 W. Preikschat, Wideo jako metafora, przeł. K. Krzemieniowa, [w:] Po kinie?... Audiowizualność w epoce przekaźników elektronicznych, Kraków 1994, s. 230.

20 S. Eisenstein, Wybór pism, przeł. L. Hochberg, red. R. Dreyer, Warszawa 1959, s. 54 n.

21 T. Miczka, A. Helman, Montaż, [w:] Słownik pojęć filmowych, t. 9. Ruch, czas, przestrzeń, montaż, red. T. Miczka, Katowice 1998, s. 162. 
matyki uzupełnia własnymi uwagami, tworząc nam tym samym czytelny wykaz komponentów budujących poetykę wideoklipu. Wyróżnia ona między innymi interpunkcję filmową, polegającą na wyodrębnianiu poszczególnych elementów filmu w toku narracji filmowych za pomocą technik montażowych, nakładanie na zapis filmowy form abstrakcyjnych bądź symboli wizualnych (na przykład w klipie Aphex Twin, Ageispolis), stosowanie błędu fotograficznego, polegającego na celowym manipulowaniu obrazem poprzez użycie grubego ziarna ${ }^{22}$, nieostrości bądź innych środków artystycznego wyrazu (wykorzystane chociażby w Roxette, Sleeping in My Car), symultaniczność obrazową, a także współistnienie kilku planów (vide przenikające się obrazy w Breathe Again Toni Braxton) czy zabawy kolorem (zarówno redukcja, jak i eksplozja barw - Jarecka podaje tu przykład amerykańskiej wersji klipu Cornflake Girl Tori Amos) lub stosowanie klamry kompozycyjnej (na przykład w teledysku do piosenki Eltona Johna Believe) ${ }^{23}$.

Elementy interpunkcji, kompozycyjna klamra, narracyjna symultaniczność czy współistnienie kilku planów to przykładowe składniki wideoklipowej poetyki, dzięki którym możemy wykazać bezpośredni związek sztuki wideoklipu z literaturą (czy szerzej — z językiem werbalnym). Na taką relację wskazuje Ryszard Kluszczyński, który pisze:

Związki z literaturą i muzyką są aktywnie obecne w większości odmian sztuk wideo, kształtując ich charakter medialny i artystyczny. Wspomniane związki powołują także do istnienia specyficzne gatunki zdominowane przez ten typ relacji, na przykład wideoklip ${ }^{24}$.

Podkreśla on nawet „dominację tego typu relacji” w przypadku wideoklipów. W tym miejscu musimy zaznaczyć, choć wydaje się to oczywiste, że teledysk muzyczny to nie tylko obraz, ale i tekst, który jest w założeniu podstawą utworu poddanego wizualnej interpretacji ${ }^{25}$. Tekst utworu muzycznego, będący specyficzną formą wypowiedzi artystycznej, mieści się w ramach pewnej ustalonej konwencji, realizuje konkretne cele, a proces jego powstawania jest całkowicie podporządkowany przyjętym przez twórcę intencjom.

Temat celowości, intencji nadawcy oraz dynamiki tekstu i jego struktury podjął Jerzy Żmudzki w studium, które zamieszczone zostało w zbiorze Tekst w kontekście. Badacz zwraca w nim uwagę przede wszystkim na uzależnienie powodzenia sytuacji komunikacyjnej od motywu, definiowanego jako „uprzedmiotowiona potrzeba czynności komunikacyjnej, z której wynika działanie o określonym kie-

${ }^{22}$ Szumy w postaci drobnych kropek, pojawiające się przy zwiększaniu czułości filmu na światło. Powiększenie ziarna skutkuje obniżeniem rozdzielczości obrazu, rozumianej jako zdolność do rejestracji szczegółów.

23 U. Jarecka, Świat wideoklipu..., s. 129-134.

24 R. Kluszczyński, Film, wideo, multimedia. Sztuka ruchomego obrazu w erze elektronicznej, Warszawa 1999, s. 79-80.

25 Istnieją oczywiście teledyski do utworów instrumentalnych, przedmiotem moich refleksji są jednak klipy do utworów, w których można wykazać komplementarność wszystkich trzech podstawowych warstw sztuk audiowizualnych — obrazu, dźwięku i tekstu. 
runku, zgodnie z wyróżnionymi celami” ${ }^{26}$. Podkreśla jednocześnie, że „każde działanie - jako dochodzenie do wyznaczonego celu — osadzone jest w konkretnych realiach [...], w określonej sytuacji, od której nie można abstrahować. I ta właśnie sytuacja determinuje aspekt operacyjny działania, ustalając sposób realizacji danego celu (aspekt illokucyjny)"27. Nadawca tekstu musi zatem ustalić obligatoryjne warunki dla zabiegów, które pozwolą mu osiągnąć zamierzony cel, lub też wskazać na operacje subsydiarne niezbędne, aby owe warunki zaistniały. Tworzy on tym samym szczegółowy plan postępowania, który realizowany jest za pomocą obranej później strategii. Żmudzki proces ten określa jako proces top down i tłumaczy go jako ,rozkładanie celu nadrzędnego na podcele, które muszą być zrealizowane, zanim osiągnięty zostanie cel nadrzędny" ${ }^{28}$. W ten sposób tworzą się bloki zintegrowanych czynności, nadające tekstowi konkretną strukturę i wpływające bezpośrednio na jego dynamikę.

Mechanizmy poprzedzające konstrukcje tekstu i jego wytwarzanie mają charakter procesów mentalnych i wypełniają swymi treściami wspomnianą wcześniej strukturę intencji, tworząc konfigurację postaw nadawcy. W przypadku przekazu wspartego materiałem wideo środki służące realizacji założonej intencji ulegają znacznemu poszerzeniu. Sama treść zostaje wsparta bogatym (mniej lub bardziej) materiałem wizualnym, który istotnie wpływa na proces odbioru komunikatu zawartego na poziomie treści. Symbole i znaczenia ukryte w tekście zostają zwizualizowane, ich materializacja polega na odwołaniu do rozmaitych obiektów przestrzennych, występujących w wideoklipie postaci i rekwizytów, a multimedialna forma komunikatu pozwala na reinterpretację pierwotnego, zakodowanego w tekście znaczenia. Tekst zostaje nie tyle wypowiedziany, ile odegrany. Pozwala to odbiorcy bardziej szczegółowo przeanalizować zawartą w nim treść.

Robert-Alain de Beaugrande i Wolfgang Dressler we Wstępie do lingwistyki tekstu wskazują na fakt istnienia różnych typów tekstów. Powodzenie interpretacyjne będzie więc uzależnione dodatkowo od formy, poziomu organizacji i użytych w obrębie utworu środków stylistycznych. Zrozumiałe jest, że występują zasadnicze różnice między tekstami naukowymi a poetyckimi. Te przeznaczone do wykonywania na scenie, a więc również stanowiące podstawę utworów muzycznych, bliższe są w swej budowie utworom poetyckim niż naukowym. Dopuszcza się w nich modyfikacje konwencji wyrażeń, które mogą powodować obniżenie informatywności, co jednak nie pociąga za sobą znacznych utrudnień interpretacyjnych, gdyż odbiorca tego typu dzieła akceptuje jego formę i konwencję, a więc godzi się na nie i rozumie zastosowane modyfikacje, reorganizacje wiedzy o świecie czy zawieszenie podstawowych faktów w organizacji świata tekstu ${ }^{29}$. W przypad-

26 J. Żmudzki, Dynamika tekstu a jego struktura, [w:] Tekst w kontekście. Zbiór studiów, red. T. Dobrzyńska, Wrocław 1990, s. 149.

27 Ibidem.

28 Ibidem.

29 R.A. de Beaugrande, W. Dressler, Wstęp do lingwistyki tekstu, przeł. A. Szwedek, Warszawa 1990, s. 199.

Literatura i Kultura Popularna XXVII, Wrocław 2021

(C) for this edition by CNS 
ku tekstów muzycznych nie wystarczy jednak interpretacja czysto semantyczna, odbiorca musi dysponować konkretną wiedzą o świecie i na tej podstawie rozpoznawać i stosować liczne presupozycje kontekstowe. W teledyskach dodatkowymi elementami spajającymi znaczenia i konteksty są gesty i mimika, które znacząco wpływają na spójność obrazu z treścią.

Dopiero tak kompleksowo potraktowany wideoklip może być obiektem wnikliwej i wielopłaszczyznowej analizy. Połączenie trzech kodów — audialnego, wizualnego i tekstowego — tworzy niejednokrotnie złożony komunikat polisemiotyczny, który dekodujemy, często nie uświadamiając sobie zaangażowania osobnych procesów myślowych przyporządkowanych do interpretacji każdego $\mathrm{z}$ wymienionych kodów. Teledysk jako forma konceptualnego wideo, które realizuje fabułę utworu, korelując obraz z treścią, bywa nierzadko medium nielinearnym. Kluszczyński, wspominając o owej nielinearności multimediów, wyróżnia strategie, dzięki wykorzystaniu których następowało przekroczenie linearności w sztuce filmowej na drodze zaburzenia sukcesywności dzieła, i dzieli owe strategie na trzy grupy ${ }^{30}$. Pierwsza $z$ nich zmierzała jego zdaniem do uporządkowania obrazów w struktury poetyckie; druga zastępuje odrzucone relacje fabularne uwypuklonymi więzami syntagmatycznymi, łącząc poszczególne składniki filmu za pomocą układów rytmicznych (wykorzystując parametry czasu, dynamiki i kierunku); a wreszcie trzecia grupa powołuje do istnienia filmy przełamujące i porzucające struktury fabularne przez skierowanie uwagi odbiorców ku ontologicznej charakterystyce kina (to swoista autoanaliza, której celem jest zbadanie filmu jako medium). Przekraczanie linearności w sztuce klipowej odbywa się głównie z zastosowaniem strategii scharakteryzowanych w dwóch pierwszych grupach.

Przenikanie technik filmowych (a więc także tych stosowanych w przypadku wideoklipów) do literatury, szczególnie prozy strumienia świadomości, opisuje Robert Humphrey, który w pracy Strumień świadomości w powieści nowoczesnej wyróżnia techniki związane z montażem czasowym i przestrzennym ${ }^{31}$. Badacz wskazuje tu na prymarną rolę montażu jako podstawowego środka filmowego, na który składają się, wymieniane wcześniej, cięcia, wielość ujęć, zbliżenia, zwolnienia, retrospekcje czy panorama. Wymienione środki pomocnicze według autora Strumienia świadomości służą przede wszystkim przezwyciężeniu dwuwymiarowego ograniczenia ekranu, uzyskaniu efektu potoku zdarzeń bądź zwróceniu uwagi na subiektywne szczegóły 32 .

Humphrey popiera swoje rozważania przykładami montażu w powieściach Jamesa Joyce'a i Virginii Woolf, ukazując, jak owi pisarze manipulują czasem i przestrzenią w swoich tekstach. Istota wyrażania ruchu i współistnienia ma tę samą wartość w przypadku literatury co wideoklipów. Próba prezentacji tego, co

30 R. Kluszczyński, op. cit., s. 202.

31 R. Humphrey, Strumień świadomości - techniki, przeł. S. Amsterdamski, „Pamiętnik Literacki" 1970, nr 4 (61), s. 255-283.

32 Ibidem, s. 275. 
niestatyczne i nieześrodkowane, ma na celu przedstawienie dwoistego aspektu życia ludzkiego. Humphrey ilustruje wykorzystanie środków filmowych na przykładzie monologu wewnętrznego Klarysy, bohaterki powieści Virginii Woolf Pani Dalloway. Mnogość różnorodnych obrazów, niezależnych czasowo i przestrzennie, może przytłoczyć czytelnika, jednocześnie pozwalając mu wniknąć w psychikę bohaterki, co zdaje się głównym celem autorów powieści strumienia świadomości. Analogicznie sytuacja wygląda w przypadku analizowanego później fragmentu Ulissesa Joyce'a. Epizod obejmujący 18 scen zachodzących w różnych miejscach Dublina wiąże wszystkie obrazy drobnymi szczegółami, które wskazują, że odbywają się one mniej więcej w tym samym czasie ${ }^{33}$. Humphrey, głównie na przykładzie twórczości Joyce'a i Woolf, pokazuje nam, jak filmowe techniki przenikają do świata literatury i jaka płynie z tego korzyść dla czytelnika. Dzięki umiejętnemu montażowi nagłe włączanie jakiegoś wątku lub nieoczekiwane przerwanie go przestaje nas zaskakiwać, a taka powieść staje się dla odbiorcy bardziej plastyczna. Śledzimy akcję tak, jakbyśmy oglądali film, przy czym możliwość wniknięcia w psychikę bohatera, a także podążanie za kilkoma wątkami jednocześnie jawi się jako intelektualne wyzwanie - owo „łączenie kropek”, rozpoznawanie i natychmiastowe porządkowanie nośników znaczeń bywa sprawdzianem naszych odbiorczych kompetencji. Taka metoda przekracza i modyfikuje konwencjonalne bariery i ograniczenia czasowo-przestrzenne, co jest jedną z głównych cech sztuk audiowizualnych, a co — jak widzimy — ma swoje zastosowanie również w literaturze.

Wszystkie wymienione elementy specyficznej, różnolitej poetyki wideoklipu muzycznego są jednocześnie składowymi strategii wizualnej, którą realizują autorzy tej formy (zarówno jej reżyserzy, jak i sami artyści). W książce zatytułowanej Komunikacja wizualna Bo Bergström opisuje najistotniejsze elementy strategii komunikacji wizualnej, które decydują o jej skuteczności, efektowności i efektywności ${ }^{34}$. Drugi rozdział poświęca narracji jako niezwykle ważnemu czynnikowi spajającemu przekaz analizowanego materiału, zwracając szczególną uwagę na rolę wstępu, tak zwanego set-up'u, w przypadku materiału wideo. Angażuje on widza i zmusza do bacznego obserwowania rozwoju wydarzeń, jednocześnie wprowadzając $\mathrm{w}$ dramaturgię utworów.

Bergström, mówiąc o obrazach i ich wykorzystaniu w komunikacji wizualnej, podaje za francuskim teoretykiem semiologii Rolandem Barthes'em dwie kategorie obrazu: studium — odnoszące się od ogólnych obserwacji otaczającego nas świata, możliwe do opisania słowami, i punctum — coś niepokojącego, trudnego do opisania, zmuszającego do zastanowienia, szukania przyczynowości i skutków ${ }^{35}$. Punctum w obrazie budzi emocje, tworzy kolejne warstwy znaczeniowe, skupia uwagę odbiorcy, jednocześnie go angażując. Umiejętna synteza studium

33 Ibidem, s. 277.

34 B. Bergström, Komunikacja wizualna, przeł. J. Tarnawska, Warszawa 2009.

35 Ibidem, s. 158. 
i punctum prowadzi do suspensu, który w dużej mierze decyduje o tym, że oglądany film czy klip są dla odbiorcy ciekawe.

Połączenie języka wizualnego i werbalnego tworzy uniwersalny trzeci język, który staje się podstawą komunikacji werbalno-wizualnej. Zespolone słowo i obraz oddziałują na odbiorcę zdecydowanie mocniej (i inaczej), niż ma to miejsce w przypadku oddzielnych komunikatów werbalnych i wizualnych ${ }^{36}$. Bergström, podobnie jak wcześniej Hendrykowski i Preikschat, podkreśla, że tekst i obraz mają swoje tempo. Udana kompilacja obu tych środków sprawia, że zyskują one wspólny rytm, co dobrze wpływa na komunikat ${ }^{37}$. Zaburzenie tej rytmicznej spójności należy traktować jako zakłócenie płynności i jasności przekazu, co komplikuje bądź uniemożliwia jego zrozumienie ${ }^{38}$.

Wspomniany już Barthes pisze o „retoryce obrazu”, ściśle wiążąc obraz (zarówno w statycznej formie fotografii bądź dzieła malarskiego, jak i obraz filmowy) z językiem, gdyż — jak zauważa — „nie tylko językoznawcy doszukują się w obrazie natury językowej" ${ }^{39}$. Tym samym zwraca uwagę na potoczne pojmowanie obrazu jako reprezentującego sens (używa nawet bardziej „obrazowego" terminu - résurrection, 'wskrzeszenie sensu') i jednocześnie przywołuje dwa opozycyjne stanowiska. Zwolennicy pierwszego z nich głoszą systemową prymitywność obrazu względem języka, co stoi w sprzeczności z poglądem zwolenników stanowiska mówiącego o niewysłowionym bogactwie obrazu, którego wyczerpanie nie jest możliwe w znaczeniu. Barthes uzależnia prawidłowe odczytanie obrazu od rozpoznania i wyodrębnienia trzech typów przekazu w nim zakodowanego. Pierwszy z nich to przekaz językowy (odsyłający do kodu językowego odbiorcy lub — gdy jest to komunikat obcojęzyczny — jego kompetencji językowych), drugi to ikoniczny przekaz kodowany (suma znaków tworzących spójną całość, których odczytanie wymaga wiedzy o charakterze ogólnokulturalnym, odsyłających do globalnych elementów znaczonych; signifié), trzeci zaś to ikoniczny przekaz niekodowany (przekaz dosłowny, odpowiadający literze obrazu; signifié w tym typie przekazu utworzone są przez rzeczywiste przedmioty, występujące w scenie, signifiant zaś przez te same przedmioty zobrazowane) ${ }^{40}$. Oczywiście liczba odczytań obrazu jest uzależniona od wiedzy i kompetencji samego odbiorcy, co

${ }^{36}$ W Semiotyce filmu pisze o tym Jurij Łotman; zespoleniu słownej narracji z ruchomym obrazem poświęca osobny rozdział (zob. idem, Semiotyka filmu, przeł. J. Faryno, Warszawa 1983, s. 89). Później w rozdziale Fabuła filmu wspomina także o istotnej roli połączeń muzyczno-obrazowych (ibidem, s. 143).

37 B. Bergström, op. cit., s. 223.

38 Oczywiście istnieje grupa twórców, którzy intencjonalnie dążą do zakłócenia wewnętrznej równowagi elementów audiowizualnego komunikatu, działając w myśl eksperymentalnych idei artystycznej awangardy, są to jednak twórcy, których klipy adresowane są do konkretnej, kompetentnej grupy odbiorców, a same nagrania nie mają charakteru komercyjnego.

39 R. Barthes, Retoryka obrazu, przeł. Z. Kruszyński, ,Pamiętnik Literacki” 1985, nr 3 (76), s. 289

40 Ibidem, s. 290-292.

Literatura i Kultura Popularna XXVII, Wrocław 2021

(C) for this edition by CNS 
jednak istotne - współistnienie wymienionych trzech typów przekazu ma swoje zastosowanie także przy analizie wideoklipów, które są przecież ruchomymi obrazami w znakomitej większości wspartymi tekstem (utwór słowno-muzyczny jest więc materiałem, który możemy badać $\mathrm{z}$ wykorzystaniem narzędzi zaproponowanych przez Barthes’a, właśnie dlatego że w wideoklipach artykułowane jest zarówno słowo, jak i dźwięk oraz obraz).

Przywołane przykłady dają nam zaledwie zarys tego, jak niejednorodnym strukturalnie gatunkiem jest wideoklip muzyczny. Co jednak wydaje się najistotniejsze - we wszystkich analizowanych aspektach pojawia się wspólny mianownik - porównanie (i współzależność) sztuk audiowizualnych z językiem. Mowa nawet o komunikacji wizualnej, a więc o motywowanym intencjami nadawcy procesie, który zakłada tworzenie przekazów językowych w celu ich późniejszej interpretacji przez odbiorcę. Język ten ma swoją gramatykę i rytm, podobnie jak język werbalny posługuje się systemem znaków i symboli. Komunikaty wizualne i audiowizualne mają także swoją poetykę, której elementy wskazała między innymi Urszula Jarecka. Mając świadomość współistnienia i przenikania się sztuk plastycznych, wizualnych i audiowizualnych, musimy uświadomić sobie, że składają się one z rozmaitych zespołów środków, wśród których istotną rolę odgrywają też środki prymarnie uznawane za językowe (na przykład za tropy i figury). W związku z tym mowa o języku architektury, języku malarstwa czy języku filmu (czyli także wideoklipu).

Badacz kultury popularnej zajmujący się analizowaniem tego typu polisemiotycznych tekstów audiowizualnych korzysta zatem z osiągnięć językoznawstwa i literaturoznawstwa, przenosząc je na grunt badań nad heterogenicznym języ ki em wideoklipów. Niewątpliwie swą wiedzę powinien uzupełniać również o znajomość tekstów z zakresu muzykologii i teorii muzyki. Wszak muzyczne środki gramatyczne (takie jak rytm, melodia, dynamika, artykulacja) są podstawą dekodowania utworu muzycznego, będącego jednym z elementów wideoklipu muzycznego. Zdaje się więc, że badacz oddający się analizie wideoklipów musi być po części filmoznawcą, muzykologiem i literaturoznawcą, gatunek ten to bowiem nie tylko obraz, muzyka czy tekst, ale ich pełnoprawne połączenie, dzięki któremu powstaje wartość naddana, dobitnie świadcząca o swoistości wideoklipu jako medium.

\section{Bibliografia}

\section{Opracowania}

Balcerzan E., W stronę genologii multimedialnej, „Teksty Drugie. Teoria literatury/krytyka/interpretacja" 1999, nr 6 (59).

Barthes R., Retoryka obrazu, przeł. Z. Kruszyński, „Pamiętnik Literacki” 1985, nr 3 (76).

Literatura i Kultura Popularna XXVII, Wrocław 2021

(C) for this edition by CNS 
Baudrillard J., Gra resztkami, przeł. A. Szahaj, [w:] Postmodernizm a filozofia, red. S. Czerniak, A. Szahaj, Wydawnictwo IFiS PAN, Warszawa 1996.

Beaugrande R.A. de, Dressler W.U., Wstęp do lingwistyki tekstu, przeł. A. Szwedek, Wydawnictwo Naukowe PWN, Warszawa 1990.

Bergström B., Komunikacja wizualna, przeł. J. Tarnawska, Wydawnictwo Naukowe PWN, Warszawa 2009.

Eisenstein S., Wybór pism, przeł. L. Hochberg, red. R. Dreyer, Wydawnictwo Artystyczne i Filmowe, Warszawa 1959.

Głowiński M., Kostkiewiczowa T., Okopień-Sławińska A., Sławiński J., Słownik terminów literackich, red. J. Stawiński, Zakład Narodowy im. Ossolińskich, Wrocław 1998.

Hendrykowski M., Semiotyka ruchomych obrazów, Wydawnictwo Naukowe UAM, Poznań 2014. Hendrykowski M., Stownik terminów filmowych, Wydawnictwo Ars Nova, Poznań 1994.

Humphrey R., Strumień świadomości - techniki, przeł. S. Amsterdamski, „Pamiętnik Literacki” 1970, $\mathrm{nr} 4$ (61).

Jarecka U., Od teledysku do wideoklipu, [w:] Nowe media w komunikacji społecznej w XX wieku, red. M. Hopfinger, Oficyna Naukowa, Warszawa 2002.

Jarecka U., Świat wideoklipu, Oficyna Naukowa, Warszawa 1999.

Kinder M., Teledyski a widz: telewizja, ideologia i marzenia senne, „Przekazy i Opinie” 1988, nr $1-2$.

Kopaliński W., Słownik wyrazów obcych i zwrotów obcojęzycznych, Świat Książki, Warszawa 2000.

Kluszczyński K., Film, wideo, multimedia. Sztuka ruchomego obrazu w erze elektronicznej, Instytut Kultury, Warszawa 1999.

Łotman J., Semiotyka filmu, przeł. J. Faryno, Wiedza Powszechna, Warszawa 1983.

Miczka T., Helman A., Stownik pojęć filmowych, t. 9. Ruch, czas, przestrzeń, montaż, red. T. Miczka, Wydawnictwo UŚ, Katowice 1998.

Nalikowski M., Estetyka wideoklipu, „Akcent” 1991, nr 1.

Preikschat W., Wideo jako metafora, przeł. K. Krzemieniowa, [w:] Po kinie?... Audiowizualność w epoce przekaźników elektronicznych, Wydawnictwo Universitas, Kraków 1994.

Stachówna G., O wideoklipach, „Powiększenie” 1987, nr 3-4.

Virilio P., Prędkość i polityka, przeł. S. Królak, Wydawnictwo Sic!, Warszawa 2008.

Zawojski P., Elektroniczne obrazoświaty. Między sztuka a technologia, Wydawnictwo Szumacher, Kielce 2000.

Żmudzki J., Dynamika tekstu a jego struktura, [w:] Tekst w kontekście. Zbiór studiów, red. T. Dobrzyńska, Zakład Narodowy im. Ossolińskich, Wrocław 1990.

\title{
Źródła internetowe
}

Wideoklip, Wikipedia, https://bit.ly/3eCsgpo (dostęp: 8.09.2020).

\section{Poetics of Music Video}

\author{
Summary
}

Music video as a specific genre of audiovisual arts, deriving directly from tradition of film, television and music programs, became massive promotion and visual communication tool for artists at the turn of 70's/80's. Mentioned many times in articles about music videos, its dependence on other art fields, such as film, musical, theater arts, plastic arts etc., only strengthens us in belief 
that music video is an enormous hybrid form, being heir to aforementioned forms. At this intertextual base, music video has developed its own language. Cognizance and description of its components, understanding of connection rules and the essence of its individual elements is the main aim of this article. By pointing to coexistence and correlations of components such as rhythm, tempo, tone, editing etc., the text also emphasizes similarity of the music video language to the language of literature and other arts which use the same tools. 
Literatura i Kultura Popularna XXVII, Wrocław 2021

(C) for this edition by CNS 